\title{
Review
}

\section{Late arrhythmia in patients with repaired tetralogy of Fallot: who is at risk?}

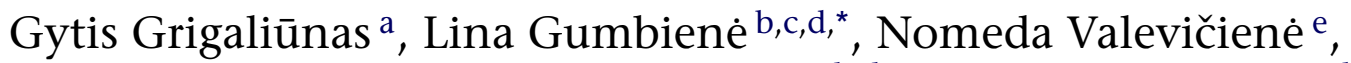 \\ Mindaugas Matačiūnase e, Virgilijus Tarutis b,d, Germanas Marinskis ${ }^{b, c}$, \\ Audrius Aidietis ${ }^{b, c}$ \\ a Faculty of Medicine, Vilnius University, Vilnius, Lithuania \\ b Clinic of Cardiovascular Diseases, Faculty of Medicine, Vilnius University, Vilnius, Lithuania \\ ${ }^{c}$ Centre of Cardiology and Angiology, Vilnius University Hospital Santariškiu Klinikos, Vilnius, Lithuania \\ d Centre of Cardiac Surgery, Vilnius University Hospital Santariškiu Klinikos, Vilnius, Lithuania \\ e Department of Radiology, Nuclear Medicine and Medical Physics, Faculty of Medicine, Vilnius University, Vilnius, Lithuania \\ Received 3 November 2014; accepted 27 February 2015
}

\begin{abstract}
Summary
Tetralogy of Fallot (TOF) is the most common cause of cyanotic congenital heart defect. Over the last century, the life expectancy of TOF patients has significantly improved. This, however, has brought new challenges both to patients and their health-care providers, the main of them being late arrhythmia. Ironically, late arrhythmia is predominantly generated due to the fibrotic scars caused by the life-saving surgical repair. Once the first two mainly arrhythmia-free decades after the repair pass, the risk of developing late arrhythmia and, therefore, SCD becomes substantial. Consequently, young adults with repaired Tetralogy of Fallot (rTOF) require careful outpatient monitoring.

There have been many attempts to predict the risk of life-threatening arrhythmia in rTOF patients. This has led to the defining of various risk factors, ranging from the widely used QRS prolongation to novel predictors, derived from cardiac magnetic resonance (CMR) based anatomical findings (left ventricular dyssynchrony indexes, right ventricular output tract akinetic length, right ventricular mass-to-volume ratio). The latter predictors have recently established CMR as a tool of high significance in evaluation of rTOF patients.

Although the role of Holter monitoring findings in rTOF patient-assessment remains unclear, it may be useful in those who are 25 years and older. Implantable cardioverter-defibrillator (ICD) implantation is the first-line treatment for secondary prevention of sudden cardiac death (SCD). rTOF patients suffer from the highest rate of inappropriate and the lowest rate of appropriate ICD shocks, when compared to other congenital heart diseases. As a consequence, ICD implantation for primary SCD prevention should be carefully weighed. Catheter-based ablation therapy leads to high rate of initial success when abolishing monomorphic ventricular tachycardia and intra-atrial reentrant tachycardia, however recurrence rates remain high.
\end{abstract}

Seminars in Cardiovascular Medicine 2015; 21:1-8

Keywords: tetralogy of Fallot, late arrhythmia, sudden cardiac death, risk factors, ventricular tachycardia

\section{Introduction}

Tetralogy of Fallot (TOF) is the most common cause of cyanotic congenital heart disease (CHD) [1]. Since Lillehei succeeded complete intracardiac repair in 1954, tremendous advances in cardiac surgery have significantly lowered peri-

\footnotetext{
* Corresponding address: Lina Gumbienė, Clinic of Cardiovascular Diseases, Faculty of Medicine, Vilnius University, M.K. Čiurlionio 21, Vilnius 03101, Lithuania.

E-mail: lina.gumbiene@santa.lt (L. Gumbienè).
}

operative mortality rates dropping from $50 \%$ to $2 \%[2,3]$.

However, long-term survival of TOF patients still does not allow reaching the life expectancy of the general population. Patients who undergo repair of TOF present with a survival rate of approximately $90 \%$ after 30 years postoperatively $[4,5]$. Late mortality rate varies with age, however, it significantly rises at 25 years after the operation from $0.24 \% / y$ to $0.94 \% / y$ [6]. More than half of late mortality is related to CHD, namely sudden cardiac death (SCD) ( 30\%) and heart failure (HF) (> 20\%) [7]. 
Ventricular arrhythmias were linked to SCD several decades ago [8]. Regardless of knowledge of various identified risk factors for late arrhythmia, it is still insufficient to predict and therefore prevent related adverse future events.

Our aim was to review the existing evidence concerning arrhythmia-related morbidity and mortality in patients with repaired TOF (rTOF). Specifically, we present the following topics: (1) prevalence of types of arrhythmia and their individual properties, (2) risk factors for development of late arrhythmia and optimal diagnostic techniques for their detection, (3) treatment (catheter ablation and drug therapy) and (4) preventive approaches (implantable cardioverterdefibrillator (ICD) for primary and secondary prevention, pulmonary valve replacement, operative timing and type).

\section{Methods}

The search for suitable articles was conducted by using "Fallot tetralogy" as the main along with "arrhythmia", "ventricular tachycardia", "risk", "stratification", "sudden cardiac death", "prevention", "treatment" as additional keywords. The search was carried using MEDLINE database. We selected relevant articles published within the last 7 years, but did not exclude highly referenced older publications that were out of our target-time period. We also checked the lists of references of found articles and used significant publications for our work. Only articles written in English were reviewed. The search was carried out in May, 2014.

\section{Late arrhythmia in rTOF patients}

Late arrhythmias remain a major worry in the population of rTOF, due to the fact that a larger proportion of patients develop symptomatic arrhythmia compared with other CHDs [9]. Patients are predominantly arrhythmia-free for the first two decades subsequent to the corrective surgery [9-11]. During the first 35 years postoperatively, ventricular tachycardia (VT) with the prevalence of $\sim 15 \%$ of rTOF patients is most common. However, at 45 years after the repair atrial fibrillation/intraatrial reentrant tachycardia (AF/IART) overreach the rate of VT and can be found in more than $50 \%$ of rTOF population using 12-lead ECG, ambulatory $24 \mathrm{~h}$ ECG or implantable cardiac device [9].

It is believed that a fraction of late arrhythmias in rTOF patients are acquired due to the formation of myocardial substrate caused by fibrotic scars after the repairing surgery $[12,13]$. Other long-standing risk factors are chronic pulmonary regurgitation (PR) and right ventricular outflow tract (RVOT) aneurysm which commonly coexist and have a proarrhythmic role [11]. According to Therrien et al., 39\% of the rTOF patients with PR experience episodes of sustained VT or non-sustained VT. Once rTOF patients with PR undergo pulmonary valve replacement surgery, this rate decreases down to $21 \%$ $(p=0.005)$ [14]. As for supraventricular arrhythmias, they are present in $70 \%$ of rTOF patients with tricuspid regurgitation, which leads to the right atrial dilation, therefore provoking rhythm disturbances [10].

\section{Sudden cardiac death}

Sudden cardiac death (SCD) is reported to account for $30 \%$ of late deaths in patients with rTOF [15]. It was proved 40 years ago that SCD is attributed to ventricular tachyarrhythmias [16]. Since then, several studies have found SCD as the most prominent element leading to late patient mortality $[6,17]$.

Many studies have been run in order to develop a reliable tool for risk stratification in patients with rTOF, who are vulnerable to main adverse cardiac outcomes, mainly SCD (Table 1). Despite the researchers' endeavour to improve early risk stratification, it is yet unknown whether it leads to improved outcomes in the targeted patient population. Several clinical values associated with SCD in rTOF patients are similar to the risk factors for SCD in patients with ischemic and dilated cardiomyopathy: supraventricular tachycar-

Table 1.

Risk factors for ventricular tachycardia and sudden cardiac death in patients with repaired tetralogy of Fallot

Older age at the time of repair

Older age after repair (chronological)

Palliative shunting prior to the radical repair

Moderate or severe PR

RV size enlargement, increased RV volume

RV hypertrophy (increased mass ratio $>0.3$ )

Documented history of AT

RV dysfunction

LV dysfunction

Prolonged QRS duration on ECG ( $\geq 180 \mathrm{~ms}$ )

Positive programmed ventricular stimulation

LV dyssynchrony indexes

RVOT akinetic length (CMR)

PR - pulmonary regurgitation; LV - left ventricular; RV - right ventricular; AT - atrial tachyarrhythmias; RVOT - right ventricular outflow tract. 
dia (SVT), increased QRS ( $\geq 180 \mathrm{~ms})$ duration, prolonged QT dispersion, left ventricular systolic dysfunction [18].

\section{Ventricular arrhythmias}

Occurrence of sustained VTs in rTOF patients can be explained by macro-reentrant mechanism which causes this kind of dysrhythmia as was found during electrophysiological studies [19-22]. Ventricular rhythm disturbances often co-exist alongside lesions of the right heart pulmonary and tricuspid regurgitation, RVOT aneurysm, which appear due to cardiac surgical manipulations, creating these macro-reentrant circuits [11].

Induced sustained VTs by programmed ventricular stimulation in patients with rTOF were previously found as diagnostic predictors for clinical VT or SCD [23]. However, it was later described as a screening tool lacking in predictive value [24].

\section{Supraventricular arrhythmias}

During a long-term follow-up 20-30\% of rTOF patients develop atrial reentrant arrhythmias (intra-atrial reentrant tachycardia (IART), atrial fibrillation (AF)) $[9,25]$. Within the group of 556 patients with rTOF, atrial tachyarrhythmias had the rate of 20.1 (95\% CI 17.0-23.6) with intra-atrial reentrant tachycardia (IART) being the most common of them (11.5\%) [9]. Right atrial dilation, linked to TOF, contributes to IART being mainly a right-sided arrhythmia.

Hesselink et al. found that supraventricular arrhythmias were present in the recordings (monitor strip, routine ECG, or Holter recording) of $34 \%$ of rTOF patients (mean follow-up of 17.5 years after surgery).

Presence of documented atrial arrhythmias (described as atrial flutter, AF or SVT) in rTOF patients plays a predictive role in risk stratification for VT and SCD (HR 3.65 (95\% CI 1.75-7.62, $p=0.001)$ ) [26]. Echocardiography-based study found that most of undocumented arrhythmias were likely to be supraventricular and linked to increased right atrial (RA) size [27].

\section{Risk factors}

Role of timing and techniques of surgical repair

Definite repair of TOF is a cardiac correction relieving RVOT obstruction and closing ventricular septal defect. The early outcomes of total repair of TOF have significantly improved since the radical procedure was first introduced and now operative mortality in young infants and even neonates does not exceed $2 \%$ [28-32].

Questions related to optimal timing, appropriate techniques for the repair and the use of palliative operation beforehand remain unclear. Harmful effects have been observed to the conduction system of the heart leading to life threatening arrhythmias and SCD after TOF repair by ventriculotomy. Despite transatrial and transatrialtranspulmonary techniques showing survival rate of $>99 \%$ (including infants) and low risk of need for early re-intervention, ventriculotomy is still widely performed $[28,29,33,34]$. A retrospective study published by Niu et al. suggests right ventricular infundibulum sparing (ventriculotomy of $5 \mathrm{~mm}$ or less), which could lead to extremely low incidence of perioperative and mid-term arrhythmias [35].

Considering optimal time, the vast majority of centres tend to choose early primary elective repair in infancy, as no benefit in delay until the end of the first year of life was observed $[29,36]$. As for repair in the neonatal age, there are controversial opinions [37]. Patients under 3 months of age are linked to longer hospitalization and ventilation with the increased need of inotropic agents compared to the population over 6 months of age [38]. Modified palliative Blalock-Taussig shunting is still agreed on as useful for complex cases of patients with anomalous coronary arteries or multiple ventricular septal defects [39].

\section{Residual pulmonary regurgitation and right ventricular dilation}

A study of 793 patients by Gatzoulis et al. found at least moderate pulmonary regurgitation to be the most common haemodynamic abnormality in patients with SCD (100\%) and VT (94\%) [10]. Continuous exposure to pulmonary regurgitation leads to progressive RV dilation and dysfunction, therefore initiating adverse clinical outcomes (arrhythmias, heart failure, sudden cardiac death) $[7,40,41]$. PR is consistent with transannular patch use in TOF patients, a technique predominantly applied in the 20th century to relieve RVOT obstruction [42]. Optimal timing for late pulmonary valve replacement (PVR) after surgical TOF is crucial and needs to be chosen wisely. A recent study suggests that patients with $\mathrm{PR}$ gain $4.3 \mathrm{ml} / \mathrm{m}^{2}$ in indexed $\mathrm{RV}$ end diastolic volume (RVEDVI) annually [43]. It was thought, that PVR should be considered once RVEDVI reaches $170 \mathrm{ml} / \mathrm{m}^{2}$ or $\mathrm{RV}$ end-systolic volume index (RVESVI) reaches $85 \mathrm{ml} / \mathrm{m}^{2}$ [44], however RVEDVI threshold was later lowered to 160 $\mathrm{ml} / \mathrm{m}^{2}$ [40] and finally to $150 \mathrm{ml} / \mathrm{m}^{2}$ based on preoperative cardiac magnetic resonance (CMR) 
findings [45]. A decade ago, echocardiographic measurements were widely used to measure the severity of PR. Now CMR is accepted as the "gold standard" technique to measure PR and assess RV volume [46-48].

Indications for PVR include a combination of PR and clinical symptoms or severe PR and moderate to severe RV enlargement [47-49]. It is presumed that PVR lowers RV volume that leads to decrease in QRS duration, which works as a preventable mechanism for VT and SCD [14, 50-52]. Geva et al. carried out a randomized trial, which compared outcomes of two rTOF patient groups with pulmonary regurgitation. Those who undergone RV surgical remodeling in addition to PVR did not show any benefits within a 6 month-period after the intervention in comparison to PVR only group [53]. In patients with dilated RV (RVEDVI $\left.=196 \pm 76 \mathrm{ml} / \mathrm{m}^{2}\right)$, PVR did not play a protective role for ventricular arrhythmias and sudden cardiac death, therefore "window of opportunity" for this intervention exists and should not be missed [54].

\section{QRS prolongation}

Right bundle branch block is a common finding on ECG in TOF patients after the surgical repair $(90 \%)[55,56]$. Gatzoulis et al. demonstrated that prolonged ( $\geq 180 \mathrm{~ms}$ ) QRS duration on resting ECG is a strong predictor for late ventricular arrhythmias and SCD with the negative predictive value of $100 \%$ [57]. QRS with a duration of $\geq 180 \mathrm{~ms}$ is often present along with an enlarged heart (cardiothoracic ratio >0.5), $r=0.44, p<$ 0.001 [10]. Another study suggests moderate correlation between QRS duration and end-diastolic volume $(r=0.6(p<0.01))$ [41]. Association between prolonged QRS and asynchronous contraction of RVOT in patients with rTOF has been reported [58]. 99\% of 92 patients with previously repaired TOF from the study conducted by Babu-Narayan et al. presented with fibrotic tissue in the free wall of RVOT detected by late gadolinium enhancement CMR [59]. Asynchronous contraction in the areas of fibrotic tissue acts as a substrate for late arrhythmias through QRS prolongation, as stated previously. Cardiac resynchronization therapy could serve as a treatment strategy for regional asynchronous RV contraction [60].

\section{Left ventricular dysfunction and dyssynchrony}

A cross-sectional study of 88 rTOF patients proved LV systolic dysfunction (ejection fraction $<55 \%)$ to be an independent predictor in sudden cardiac death and sustained VTs $(\mathrm{OR}=8.05$, 95\% CI 2.14-30.2, $p=0.002$ ) [49]. Moderate or severe systolic left ventricular dysfunction (LVD), when combined with QRS duration $\geq 180 \mathrm{~ms}$, had even stronger positive predictive value (with an increase from $29 \%$ to $66 \%$ ) for SCD [61].

Although there is no definite explanation for the mechanism of LVD in rTOF patients, a probable interrelation between interventricular dyssynchrony and prolonged QRS duration is suggested [54]. Fibrotic lesions of LV, mostly found in the apex (using LGE CMR), are related with LVD as potential cause for SCD [59].

Growing evidence suggest LV dyssynchrony indexes to be the new promising measurements assessed by tissue tracking of CMR images [62]. In the patient group with history of VT or SCD, LV dyssynchrony indexes, especially maximum segmental time difference to peak circumferential strain were associated with adverse events.

\section{Right ventricular hypertrophy}

RV hypertrophy (increased myocardial mass assessed by CMR) is a significant independent predictor for SCD and sustained VT in patients with repaired TOF as found by large International Multicenter TOF Registry (INdiCaTOR) cohort study. Ratio $\geq 0.3$ of RV mass-to-volume for rTOF patients was sufficient to reach high risk regarding adverse outcomes (HR 5.04, 95\% CI 2.3-11.0, $p<0.001$ ) [26]. Additionally, LV and/or RV dysfunction and documented atrial tachyarrhythmia may independently increase the probability of life-threatening outcomes. These newly proposed risk factors should be taken into account and reassessed in the future studies.

\section{Right ventricular outflow tract akinetic region length}

Akinetic RVOT regions combined with chronic PR, emerge as the main underlying causes for late RV dysfunction in rTOF patients [63]. A prospective longitudinal study found RVOT akinetic length measured by CMR as a predictor for ventricular arrhythmias $(p=0.003)$ [64]. Those with RVOT akinetic length $>30 \mathrm{~mm}$ had worse ventricular arrhythmia-free survival (log rank $p=0.02)$.

\section{Treatment and prevention}

\section{Risk assessment by Holter monitoring}

24-h Holter monitoring is a noninvasive ambulatory method used to detect cardiac rhythm abnormalities among children and adult patients after radical repair of tetralogy of Fallot. A recent study revealed that $43 \%$ of these patients had arrhythmias on Holter monitoring, 90\% of them being asymptomatic [65]. In another study with similar rate of asymptomatic rTOF patients (83\%) most frequently recorded cumulative lifetime 
Holter findings were atrial (28\%) and ventricular (44\%) couplets/triplets, frequent premature ventricular contractions (25\%) and non-sustained VT (10\%) [66]. Early detection of arrhythmias by routine screening could lead to initial intervention by catheter ablation or ICD implantation. Findings on Holter monitoring changed the course of management for only two percent of study population with rTOF. The analysis on cost effectiveness of Holter monitoring concluded, that the method has a minor role for assessment in patients with CHD due to its low sensitivity (0.40) for future clinically significant arrhythmias [66]. However, the effectiveness differs by CHD type and age of the patient, with Holter monitoring being markedly useful in clinical management and risk assessment for rTOF patients over 25 years of age [66]. PACES/HRS Expert Consensus Statement on Arrhythmias in Adult Congenital Heart Disease recommends periodic Holter monitoring for those TOF patients who are over 35 years of age (class I, level of evidence: B) [67].

\section{Implantable cardioverter-defibrillator}

ICD therapy is aimed at preventing life-threatening arrhythmias, which could potentially lead to SCD. TOF patients constitute the largest group receiving ICD therapy when compared with patients suffering from other CHDs [68-70].

Due to the lack of randomized clinical trials and meta-analyses investigating the use of cardiac devices in CHD, indications for ICD implantation differ between different guidelines. Therefore, the recent PACES/HRS Expert Consensus Statement on Arrhythmias in Adult CHD (2014) is based on $B$ and $C$ levels of evidence only. ICD therapy is agreed to be indicated in the presence of: previously occurred cardiac arrest (due to ventricular fibrillation or haemodynamically unstable VT) with the exclusion of reversible causes, impaired left ventricular function (ejection fraction $\leq 35 \%$ ) or spontaneous sustained ventricular tachycardia followed by haemodynamic and electrophysiologic evaluation [67].

Importantly, patients with rTOF experience higher incidence of receiving inappropriate ICD shocks compared to patients with other CHDs (HR 3.6, 95\% CI 1.0-12.4, $p<0.048$ ) [71]. This often has negative impact on the mental state of these patients [69]. This should not be dismissed when treatment strategies are considered, as the population of younger patients is more prone to mental depression and poor quality of life when ICD is applied [72].

The majority of inappropriate ICD shocks were seen in patients who suffered from supraventricular tachycardia with the rate of overall unnecessary shocks of $20 \%$ [73]. In addition, rTOF patients were associated with lower appropriate shock rate when compared with other CHD (HR $0.29, p=0.02$ ) [69]. Lead failure was responsible for the largest part of complications (early and late, combined) related to ICD implantation [69].

Multi-central retrospective study by Koyak et al. described non-sustained VTs as significant predictor for appropriate ICD shocks (HR 9.1, 95\% CI 2.8-29.2, $p<0.001$ ) [71]. Indication for secondary prevention was also associated with higher risk of appropriate shocks (HR 3.6, 95\% CI 1.3-9.5, $p=0.009$ ). Importantly, larger number of first appropriate ICD shocks occurred in the first 2 years of follow-up.

\section{Catheter-based ablation therapy}

Catheter ablation is often used for patients with rTOF and other CHDs in order to abolish monomorphic VT and, therefore, reduce the need for ICD use. As for today, it stands as one of the most active fields of research over TOF, focusing on refinement of the treatment for late life-threatening rhythm disturbances.

In rTOF patients, the macro-reentry type circuits situate mainly in the anatomic isthmuses, namely between RVOT/adjacent RV scar and tricuspid annulus or between PV and septal scar, surrounded by unexcitable tissue [74]. The success rate for treating VTs in rTOF patients by ablation varies from $50 \%$ to $91 \%$ according to the studies using electroanatomic substrate-based mapping approach [74,75]. Described VT recurrence rates remain high (up to 20\%) in turn hindering wider use of this treatment strategy in patients with rTOF $[76,77]$. Effective ablation is even more complicated to achieve in patients who are haemodynamically unstable during VT. However, there is evidence implying, that non-contact mapping system could be applied for effective treatment of haemodynamically unstable VTs in patients with rTOF [76].

Cavotricuspid isthmus (CTI) and lateral right atrium (RA) wall served as conduction pathways of intraatrial macro-reentrant tachycardia (IART) circuits in $85 \%$ of rTOF and double outlet right ventricle patients [77]. Though initial success rate for AT ablations was high, $19 \%$ of the patients experienced recurrent sustained AT within 6.5 months of follow-up [78]. Recurrence rate may decrease if both the CTI and lateral RA wall are ablated, even if single substrate region is detected by mapping [77].

\section{Atrial pacing and medical therapy}

In contrast to the general population, atrial pacing did not prove to be effective in prevention of atrial arrhythmias in patients with CHD [79]. 
Medical therapy (beta-blockers and amiodarone) is only advised as a supplementary treatment option along with ICD implantation or catheter ablation in high-risk patients with lifethreatening arrhythmias [80].

\section{Conclusions}

Despite the breakthroughs in treatment of TOF patients over the last century, several challenges remain unresolved. Late arrhythmia followed by SCD is the main contributor to premature death of those with rTOF. The development of accurate risk-stratification for SCD would assist in selecting rTOF patients most in need of active prevention. Hopefully, near future will bring discoveries aimed at improving life quality and lifespan of rTOF patients.

\section{References}

[1] Hoffman JI, Kaplan S. The incidence of congenital heart disease. J Am Coll Cardiol 2002;39:1890-900.

[2] Bacha EA, Scheule AM, Zurakowski D, Erickson LC, Hung $\mathrm{J}$, Lang $\mathrm{P}$, et al. Long-term results after early primary repair of tetralogy of Fallot. I Thorac Cardiovasc Surg 2001;122:154-61.

[3] Parry AJ, McElhinney DB, Kung GC, Reddy VM, Brook MM, Hanley FL. Elective primary repair of acyanotic tetralogy of Fallot in early infancy: overall outcome and impact on the pulmonary valve. J Am Coll Cardiol 2000;36:2279-83.

[4] Murphy JG, Gersh BJ, Mair DD, Fuster V, McGoon MD, Ilstrup DM, et al. Long-term outcome in patients undergoing surgical repair of tetralogy of Fallot. $N$ Engl J Med 1993;329:593-9.

[5] Chiu S-N, Wang J-K, Chen H-C, Lin M-T, Wu E-T, Chen $\mathrm{C}-\mathrm{A}$, et al. Long-term survival and unnatural deaths of patients with repaired tetralogy of Fallot in an Asian cohort. Circ Cardiovasc Qual Outcomes 2012;5:120-5.

[6] Nollert G, Fischlein T, Bouterwek S, Böhmer C, Klinner $\mathrm{W}$, Reichart B. Long-term survival in patients with repair of tetralogy of Fallot: 36-year follow-up of 490 survivors of the first year after surgical repair. J Am Coll Cardiol 1997;30:1374-83.

[7] Nieminen HP, Jokinen EV, Sairanen HI. Causes of late deaths after pediatric cardiac surgery: a population-based study. J Am Coll Cardiol 2007;50:1263-71.

[8] Garson A Jr, Randall DC, Gillette PC, Smith RT, Moak JP, McVey P, et al. Prevention of sudden death after repair of tetralogy of Fallot: Treatment of ventricular arrhythmias. J Am Coll Cardiol 1985;6:221-7.

[9] Khairy P, Aboulhosn J, Gurvitz MZ, Opotowsky AR, Mongeon F-P, Kay J, et al. Arrhythmia burden in adults with surgically repaired tetralogy of Fallot: a multi-institutional study. Circulation 2010;122:868-75.

[10] Gatzoulis MA, Balaji S, Webber S, Siu S, Hokanson J, Poile C, et al. Risk factors for arrhythmia and sudden cardiac death late after repair of tetralogy of Fallot: a multicentre study. Lancet 2000;356:975-81.

[11] Harrison DA, Harris L, Siu SC, MacLoghlin CJ, Connelly MS, Webb GD, et al. Sustained ventricular tachycardia in adult patients late after repair of tetralogy of Fallot. J Am Coll Cardiol 1997;30:1368-73.

[12] Misaki T, Tsubota M, Watanabe G, Watanabe Y, Matumoto $\mathrm{Y}$, Ishida $\mathrm{K}$, et al. Surgical treatment of ventricular tachycardia after surgical repair of tetralogy of Fallot. Relation between intraoperative mapping and histological findings. Circulation 1994;90:264-71.

[13] Dietl CA, Cazzaniga ME, Dubner SJ, Pérez-Baliño NA, Torres AR, Favaloro RG. Life-threatening arrhythmias and RV dysfunction after surgical repair of tetralogy of Fallot. Comparison between transventricular and transatrial approaches. Circulation 1994;90:II7-12.

[14] Therrien J, Siu SC, Harris L, Dore A, Niwa K, Janousek J, et al. Impact of pulmonary valve replacement on arrhythmia propensity late after repair of tetralogy of Fallot. Circulation 2001;103:2489-94.

[15] Oechslin EN, Harrison DA, Connelly MS, Webb GD, Siu SC. Mode of death in adults with congenital heart disease. Am J Cardiol 2000;86:1111-6.

[16] James FW, Kaplan S, Chou TC. Unexpected cardiac arrest in patients after surgical correction of tetralogy of Fallot. Circulation 1975;52:691-5.

[17] Gillette PC, Yeoman MA, Mullins CE, McNamara DG. Sudden death after repair of tetralogy of Fallot. Electrocardiographic and electrophysiologic abnormalities. Circulation 1977;56:566-71.

[18] Koyak Z, Harris L, de Groot JR, Silversides CK, Oechslin EN, Bouma BJ, et al. Sudden cardiac death in adult congenital heart disease. Circulation 2012;126:1944-54.

[19] Kremers MS, Wells PJ, Black WH, Solodyna MA. Entrainment of ventricular tachycardia in postoperative tetralogy of Fallot. Pacing Clin Electrophysiol 1988;11:1310-4.

[20] Horowitz LN, Vetter VL, Harken AH, Josephson ME. Electrophysiologic characteristics of sustained ventricular tachycardia occurring after repair of tetralogy of Fallot. Am J Cardiol 1980;46:446-52.

[21] Kugler JD, Pinsky WW, Cheatham JP, Hofschire PJ, Mooring PK, Fleming WH. Sustained ventricular tachycardia after repair of tetralogy of Fallot: New electrophysiologic findings. Am J Cardiol 1983;51:1137-43.

[22] Downar E, Harris L, Kimber S, Mickleborough L, Williams W, Sevaptsidis E, et al. Ventricular tachycardia after surgical repair of tetralogy of Fallot: results of intraoperative mapping studies. J Am Coll Cardiol 1992;20:648-55.

[23] Khairy P, Landzberg MJ, Gatzoulis MA, Lucron H, Lambert J, Marçon F, et al. Value of programmed ventricular stimulation after tetralogy of Fallot repair: a multicenter study. Circulation 2004;109:1994-2000.

[24] Khairy P. Programmed ventricular stimulation for risk stratification in patients with tetralogy of Fallot: a Bayesian perspective. Nat Clin Pract Cardiovasc Med 2007;4:292-3.

[25] Roos-Hesselink J, Perlroth MG, McGhie J, Spitaels S. Atrial arrhythmias in adults after repair of tetralogy of Fallot: Correlations with clinical, exercise, and echocardiographic findings. Circulation 1995;91:2214-9.

[26] Valente AM, Gauvreau K, Assenza GE, Babu-Narayan SV, Schreier J, Gatzoulis MA, et al. Contemporary predictors of death and sustained ventricular tachycardia in patients with repaired tetralogy of Fallot enrolled in the INDICATOR cohort. Heart 2014;100:247-53.

[27] Rosianu S, Paprika D, Osztheimer I, Temesvari A, Szili-Torok T. Echocardiographic evaluation of patients with undocumented arrhythmias occurring in adults late after repair of tetralogy of Fallot. Eur J Echocardiogr 2009;10:139-43.

[28] Karl TR, Sano S, Pornviliwan S, Mee RB. Tetralogy of Fallot: favorable outcome of nonneonatal transatrial, transpulmonary repair. Ann Thorac Surg 1992;54:903-7. 
[29] Al Habib HF, Jacobs JP, Mavroudis C, Tchervenkov CI, O'Brien SM, Mohammadi S, et al. Contemporary patterns of management of tetralogy of Fallot: data from the Society of Thoracic Surgeons Database. Ann Thorac Surg 2010;90:813-20.

[30] Kim H, Sung SC, Kim SH, Chang YH, Lee HD, Park JA, et al. Early and late outcomes of total repair of tetralogy of Fallot: risk factors for late right ventricular dilatation. Interact Cardiovasc Thorac Surg 2013;17:956-62.

[31] Reddy VM, Liddicoat JR, McElhinney DB, Brook MM, Stanger P, Hanley FL. Routine primary repair of tetralogy of Fallot in neonates and infants less than three months of age. Ann Thorac Surg 1995;60:S592-6.

[32] Stellin G, Milanesi O, Rubino M, Michielon G, Bianco R, Moreolo GS, et al. Repair of tetralogy of Fallot in the first six months of life: transatrial versus transventricular approach. Ann Thorac Surg 1995;60:S588-91.

[33] Fraser CD Jr, McKenzie ED, Cooley DA. Tetralogy of Fallot: surgical management individualized to the patient. Ann Thorac Surg 2001;71:1556-63.

[34] Stewart RD, Backer CL, Young L, Mavroudis C. Tetralogy of Fallot: results of a pulmonary valve-sparing strategy. Ann Thorac Surg 2005;80:1431-9.

[35] Niu MC, Morris SA, Morales DL, Fraser CD Jr, Kim JJ. Low incidence of arrhythmias in the right ventricular infundibulum sparing approach to tetralogy of Fallot repair. Pediatr Cardiol 2014;35:261-9.

[36] Mahle WT, McBride MG, Paridon SM. Exercise performance in tetralogy of Fallot: the impact of primary complete repair in infancy. Pediatr Cardiol 2002;23:224-9.

[37] Tamesberger MI, Lechner E, Mair R, Hofer A, SamesDolzer E, Tulzer G. Early primary repair of tetralogy of Fallot in neonates and infants less than four months of age. Ann Thorac Surg 2008;86:1928-35.

[38] Vohra HA, Adamson L, Haw MP. Is early primary repair for correction of tetralogy of Fallot comparable to surgery after 6 months of age? Interact Cardiovasc Thorac Surg 2008;7:698-701.

[39] Gladman G, Mccrindle BW, Williams WG, Freedom RM, Benson LN. The modified Blalock-Taussig shunt: clinical impact and morbidity in Fallot's tetralogy in the current era. J Thorac Cardiovasc Surg 1997;114:25-30.

[40] Oosterhof T, van Straten A, Vliegen HW, Meijboom FJ, van Dijk AP, Spijkerboer AM, et al. Preoperative thresholds for pulmonary valve replacement in patients with corrected tetralogy of Fallot using cardiovascular magnetic resonance. Circulation 2007;116:545-51.

[41] Abd El Rahman MY, Abdul-Khaliq H, Vogel M, Alexi-Meskishvili V, Gutberlet M, Lange PE. Relation between right ventricular enlargement, QRS duration, and right ventricular function in patients with tetralogy of Fallot and pulmonary regurgitation after surgical repair. Heart 2000;84:416-20.

[42] Rebergen SA, Chin JG, Ottenkamp J, van der Wall EE, de Roos A. Pulmonary regurgitation in the late postoperative follow-up of tetralogy of Fallot. Volumetric quantitation by nuclear magnetic resonance velocity mapping. Circulation 1993;88:2257-66.

[43] Meagher SO, Ganigara M, Tanous DJ, Celermajer DS, Puranik R. Progress of right ventricular dilatation in adults with repaired tetralogy of Fallot and free pulmonary regurgitation. Int J Cardiol Heart Vessels 2014;3:28-31.

[44] Therrien J, Provost Y, Merchant N, Williams W, Colman J, Webb G. Optimal timing for pulmonary valve replacement in adults after tetralogy of Fallot repair. Am J Cardiol 2005;95:779-82.

[45] Buechel ER, Dave HH, Kellenberger CJ, Dodge-Khatami A, Pretre R, Berger F, et al. Remodelling of the right ventricle after early pulmonary valve replacement in children with repaired tetralogy of Fallot: assessment by cardiovascular magnetic resonance. Eur Heart J 2005;26:2721-7.

[46] Geva T, Sandweiss BM, Gauvreau K, Lock JE, Powell AJ. Factors associated with impaired clinical status in long-term survivors of tetralogy of Fallot repair evaluated by magnetic resonance imaging. I Am Coll Cardiol 2004;43:1068-74.

[47] Wald RM, Redington AN, Pereira A, Provost YL, Paul NS, Oechslin EN, et al. Refining the assessment of pulmonary regurgitation in adults after tetralogy of Fallot repair: should we be measuring regurgitant fraction or regurgitant volume? Eur Heart J 2009;30:356-61.

[48] Mooij CF, de Wit CJ, Graham DA, Powell AJ, Geva T. Reproducibility of MRI measurements of right ventricular size and function in patients with normal and dilated ventricles. J Magn Reson Imaging 2008;28:67-73.

[49] Knauth AL, Gauvreau K, Powell AJ, Landzberg MJ, Walsh EP, Lock JE, et al. Ventricular size and function assessed by cardiac MRI predict major adverse clinical outcomes late after tetralogy of Fallot repair. Heart 2008;94:211-6.

[50] Van Huysduynen BH, van Straten A, Swenne CA, Maan AC, van Eck HJ, Schalij MJ, et al. Reduction of QRS duration after pulmonary valve replacement in adult Fallot patients is related to reduction of right ventricular volume. Eur Heart J 2005;26:928-32.

[51] Vliegen HW, van Straten A, de Roos A, Roest AA, Schoof $\mathrm{PH}$, Zwinderman $\mathrm{AH}$, et al. Magnetic resonance imaging to assess the hemodynamic effects of pulmonary valve replacement in adults late after repair of tetralogy of Fallot. Circulation 2002;106:1703-7.

[52] Van Straten A, Vliegen HW, Hazekamp MG, Bax JJ, Schoof $\mathrm{PH}$, Ottenkamp J, et al. Right ventricular function after pulmonary valve replacement in patients with tetralogy of Fallot. Radiology 2004;233:824-9.

[53] Geva T, Gauvreau K, Powell AJ, Cecchin F, Rhodes J, Geva $\mathrm{J}$, et al. Randomized trial of pulmonary valve replacement with and without right ventricular remodeling surgery. Circulation 2010;122:S201-8.

[54] Tzemos N, Harris L, Carasso S, Subira LD, Greutmann M, Provost Y, et al. Adverse left ventricular mechanics in adults with repaired tetralogy of Fallot. Am J Cardiol 2009;103:420-5.

[55] Horowitz LN, Simson MB, Spear JF, Josephson ME, Moore EN, Alexander JA, et al. The mechanism of apparent right bundle branch block after transatrial repair of tetralogy of Fallot. Circulation 1979;59:1241-52.

[56] Khairy P, Marelli AJ. Clinical use of electrocardiography in adults with congenital heart disease. Circulation 2007;116:2734-46.

[57] Gatzoulis MA, Till JA, Somerville J, Redington AN. Mechanoelectrical interaction in tetralogy of Fallot: QRS prolongation relates to right ventricular size and predicts malignant ventricular arrhythmias and sudden death. Circulation 1995;92:231-7.

[58] Uebing A, Gibson DG, Babu-Narayan SV, Diller GP, Dimopoulos K, Goktekin O, et al. Right ventricular mechanics and QRS duration in patients with repaired tetralogy of Fallot: implications of infundibular disease. Circulation 2007;116:1532-9.

[59] Babu-Narayan SV, Kilner PJ, Li W, Moon JC, Goktekin O, Davlouros PA, et al. Ventricular fibrosis suggested by cardiovascular magnetic resonance in adults with repaired tetralogy of Fallot and its relationship to adverse markers of clinical outcome. Circulation 2006;113:405-13.

[60] Dubin AM, Feinstein JA, Reddy VM, Hanley FL, Van Hare GF, Rosenthal DN. Electrical resynchronization: a novel therapy for the failing right ventricle. Circulation 2003;107:2287-9. 
[61] Ghai A, Silversides C, Harris L, Webb GD, Siu SC, Therrien $\mathrm{J}$. Left ventricular dysfunction is a risk factor for sudden cardiac death in adults late after repair of tetralogy of Fallot. J Am Coll Cardiol 2002;40:1675-80.

[62] Ortega M, Triedman JK, Geva T, Harrild DM. Relation of left ventricular dyssynchrony measured by cardiac magnetic resonance tissue tracking in repaired tetralogy of Fallot to ventricular tachycardia and death. Am J Cardiol 2011;107:1535-40.

[63] Davlouros PA, Kilner PJ, Hornung TS, Li W, Francis JM, Moon JC, et al. Right ventricular function in adults with repaired tetralogy of Fallot assessed with cardiovascular magnetic resonance imaging: Detrimental role of right ventricular outflow aneurysms or akinesia and adverse right-to-left ventricular interaction. J Am Coll Cardiol 2002;40:2044-52.

[64] Bonello B, Kempny A, Uebing A, Li W, Kilner PJ, Diller GP, et al. Right atrial area and right ventricular outflow tract akinetic length predict sustained tachyarrhythmia in repaired tetralogy of Fallot. Int J Cardiol 2013;168:3280-6.

[65] Rodriguez FH, Moodie DS, Neeland M, Adams GJ, Snyder CS. Identifying arrhythmias in adults with congenital heart disease by 24 -h ambulatory electrocardiography. Pediatr Cardiol 2012;33:591-5.

[66] Czosek RJ, Anderson J, Khoury PR, Knilans TK, Spar DS, Marino BS. Utility of ambulatory monitoring in patients with congenital heart disease. Am J Cardiol 2013;111:72330.

[67] Khairy P, Van Hare GF, Balaji S, Berul CI, Cecchin F, Cohen MI, et al. PACES/HRS Expert Consensus Statement on the recognition and management of arrhythmias in adult congenital heart disease: Developed in partnership between the Pediatric and Congenital Electrophysiology Society (PACES) and the Heart Rhythm Society (HRS). Heart Rhythm 2014;11:e102-65.

[68] Khairy P, Harris L, Landzberg MJ, Viswanathan $\mathrm{S}$, Barlow A, Gatzoulis MA, et al. Implantable cardioverter-defibrillators in tetralogy of Fallot. Circulation 2008;117:363-70.

[69] Yap SC, Roos-Hesselink JW, Hoendermis ES, Budts W, Vliegen HW, Mulder BJ, et al. Outcome of implantable cardioverter defibrillators in adults with congenital heart disease: a multi-centre study. Eur Heart $J$ 2007;28:1854-61.

[70] Dore A, Santagata P, Dubuc M, Ee L. Implantable cardioverter defibrillators in adults with congenital heart disease: A single center experience. Pacing Clin Electrophysiol 2004;27:47-51.
[71] Koyak Z, de Groot JR, Van Gelder IC, Bouma BJ, van Dessel PF, Budts W, et al. Implantable cardioverter defibrillator therapy in adults with congenital heart disease: who is at risk of shocks? Circ Arrhythm Electrophysiol 2012;5:101-10.

[72] Friedmann E, Thomas SA, Inguito P, Kao CW, Metcalf M, Kelley FJ, et al. Quality of life and psychological status of patients with implantable cardioverter defibrillators. J Interv Card Electrophysiol 2006;17:65-72.

[73] Witte KK, Pepper CB, Cowan JC, Thomson JD, English KM, Blackburn ME. Implantable cardioverterdefibrillator therapy in adult patients with tetralogy of Fallot. Europace 2008;10:926-30.

[74] Zeppenfeld K, Schalij MJ, Bartelings MM, Tedrow UB, Koplan BA, Soejima K, et al. Catheter ablation of ventricular tachycardia after repair of congenital heart disease: electroanatomic identification of the critical right ventricular isthmus. Circulation 2007;116:2241-52.

[75] Morwood JG, Triedman JK, Berul CI, Khairy P, Alexander $\mathrm{ME}$, Cecchin F, et al. Radiofrequency catheter ablation of ventricular tachycardia in children and young adults with congenital heart disease. HeartRhythm 2004;1:3018.

[76] Kriebel T, Saul JP, Schneider H, Sigler M, Paul T. Noncontact mapping and radiofrequency catheter ablation of fast and hemodynamically unstable ventricular tachycardia after surgical repair of tetralogy of Fallot. J Am Coll Cardiol 2007;50:2162-8.

[77] Mah DY, Alexander ME, Cecchin F, Walsh EP, Triedman JK. The electroanatomic mechanisms of atrial tachycardia in patients with tetralogy of Fallot and double outlet right ventricle. J Cardiovasc Electrophysiol 2011;22:1013-7.

[78] Triedman JK, DeLucca JM, Alexander ME, Berul CI, Cecchin F, Walsh EP. Prospective trial of electroanatomically guided, irrigated catheter ablation of atrial tachycardia in patients with congenital heart disease. HeartRhythm 2005;2:700-5.

[79] Opic P, Yap SC, Van Kranenburg M, Van Dijk AP, Budts $\mathrm{W}$, Vliegen HW, et al. Atrial-based pacing has no benefit over ventricular pacing in preventing atrial arrhythmias in adults with congenital heart disease. Europace 2013;15:1757-62.

[80] Connolly SJ, Dorian P, Roberts RS, Gent M, Bailin S, Fain ES, et al. Comparison of beta-blockers, amiodarone plus beta-blockers, or sotalol for prevention of shocks from implantable cardioverter defibrillators: the OPTIC Study: a randomized trial. JAMA 2006;295:165-71. 